\title{
Socioeconomic factors, rather than diabetes mellitus per se, contribute to an excessive use of antidepressants among young adults with childhood onset type 1 diabetes mellitus: a register-based study
}

\author{
T. Lind $\cdot$ I. Waernbaum $\cdot$ Y. Berhan $\cdot$ G. Dahlquist
}

Received: 15 September 2011 / Accepted: 11 November 2011 / Published online: 17 December 2011

(C) Springer-Verlag 2011

\begin{abstract}
Aims/hypothesis Mood disorders, including depression, are suggested to be prevalent in persons with type 1 diabetes and may negatively affect self-management and glycaemic control and increase the risk of diabetic complications. The aim of this study was to analyse the prevalence of antidepressant $(\mathrm{AD})$ use in adults with childhood onset type 1 diabetes and to compare risk determinants for $\mathrm{AD}$ prescription among diabetic patients and a group of matched controls. Methods Young adults $\geq 18$ years on 1 January 2006 with type 1 diabetes $(n=7,411)$ were retrieved from the populationbased Swedish Childhood Diabetes Registry (SCDR) and compared with 30,043 age- and community-matched controls. Individual level data were collected from the Swedish National Drug Register (NDR), the Hospital Discharge Register (HDR) and the Labor Market Research database (LMR).

Results ADs were prescribed to $9.5 \%$ and $6.8 \%$ of the type 1 diabetes and control subjects, respectively. Female sex, having received economic or other social support, or having a disability pension were the factors with the strongest association with $\mathrm{AD}$ prescription in both groups. Type 1 diabetes was associated with a $44 \%$ (OR 1.44, 95\% CI 1.32, 1.58) higher risk of being prescribed ADs in crude analysis. When adjusting for potential confounders including sex, age and various socioeconomic risk factors, this risk increase was statistically non-significant (OR 1.11, 95\% CI 0.99, 1.21).
\end{abstract}

T. Lind $(\bowtie) \cdot$ Y. Berhan $\cdot$ G. Dahlquist

Department of Clinical Sciences, Pediatrics, Umeå University, 90187 Umeå, Sweden

e-mail: Torbjorn.Lind@pediatri.umu.se

I. Waernbaum

Department of Statistics, Umeå University,

Umeå, Sweden
Conclusions/interpretation The risk factor patterns for AD use are similar among type 1 diabetic patients and controls, and socioeconomic risk factors, rather than the diabetes per se, contribute to the increased risk of AD use in young adults with type 1 diabetes.

Keywords Adult - Antidepressant treatment .

Socioeconomic factors · Type 1 diabetes mellitus

\author{
Abbreviations \\ AD Antidepressant \\ ATC Anatomical therapeutic chemical \\ HDR Hospital Discharge Register \\ ICD International Classification of Diseases \\ LMR Labor Market Research database \\ NDR National Drug Registry \\ PIN Personal identification number \\ SCDR Swedish Childhood Diabetes Registry
}

\section{Introduction}

Psychological problems including mood disorders have long been of interest in the clinical management of type 1 diabetes mellitus, since poor metabolic control may affect cognitive function and mood. Depression on its own may also severely hamper self-control in diabetic patients thereby inducing a vicious circle of poor control and risk of future complications $[1,2]$. A number of reports have assessed the prevalence of depression among diabetic patients and a meta-analysis covering a large number of studies involving adults with different types of diabetes and using a range of methods concluded that the risk of depression was doubled among diabetic patients [3]. Even 
higher differences were indicated in a recent review covering studies on type 1 diabetic adults, in which the prevalence of depression in controlled studies was estimated to be around four times higher in the diabetic than the non-diabetic groups. However, the authors recommend that the results should be viewed with caution as different methods of diagnosis were used and the number of participants was small [4].

The SEARCH for Diabetes in Youth Study, focusing on young people (10-21 years) with diabetes using self-reported questionnaires for depression, found that $14 \%$ of the diabetic individuals experienced mild, and $8.6 \%$ moderate or severely depressed, mood [5]. A longitudinal study by Kovacs et al. [6] estimated that, after 10 years of follow up, psychiatric disorders had occurred among almost half of the patients at a mean age of 20 years and major depression had occurred in around a quarter. Few studies have related the prevalence of depression in type 1 diabetes to that in controls. Popkin et al. [7] found that the prevalence of depression among individuals with longstanding type 1 diabetes awaiting pancreas transplantation was $10.7 \%$ compared with $2.9 \%$ in their firstdegree relatives (and potential donors) [7]. Furthermore, in adults with new onset type 1 diabetes, the prevalence of depression was twice that of controls [8]. However, Kokkonen found no difference in the prevalence of depression comparing young adults with type 1 diabetes to those who were medically well [9]. Since treatment of depression may improve metabolic control in diabetes $[10,11]$ it has been suggested that screening for depression should be recommended in young patients with diabetes. Apart from the manifestation of diabetes in itself, other diabetes-specific risk factors for depression have included the occurrence of late complications, persistent poor glycaemic control and hypoglycaemia problems [12].

In the general population, female sex, lack of social support, low socioeconomic status, the occurrence of critical life events, ethnicity and some cultural factors have been associated with depression, not least among adolescents and young adults [13-16].

Most previous studies on depression in young people with diabetes are small and clinical based and the data are mainly from the USA. In this paper we use population-based Swedish databases that provide a unique opportunity to:

1. explore in a population-based study the prevalence of antidepressant (AD) use in young adults with childhood onset type 1 diabetes;

2. describe and compare risk determinants for $\mathrm{AD}$ prescription among diabetic patients and a group of matched controls.

\section{Methods}

The Swedish Childhood Diabetes Registry (SCDR) is a longitudinal research project recording incident cases of type 1 diabetes since 1 July 1977 , which to date has collected more than 16,000 prospective cases following informed consent from the parents [17]. The SCDR enrols children who are diagnosed with type 1 diabetes with onset before 15 years of age and reside in Sweden at the time of diagnosis. The level of coverage is $96-99 \%$ and is ascertained by internal revisions and matching to official population registers [18]. For the present analyses, the SCDR database was linked to the Swedish National Drug Register (NDR) and the Hospital Discharge Register (HDR) at the National Board of Health, and the Labor Market Research database (LMR) at Statistics Sweden using a unique personal identification number (PIN) [19-21]. Data from these registers have been found to be valid and have been used extensively in research [22]. We defined in advance which variables we wanted to include in the analysis. We then did a one-time withdrawal of data from the various databases, and we performed all analyses on that retrieved data. After linking, coded data sets without personal identification were returned to the researchers for further analyses. For each type 1 diabetes case, Statistics Sweden selected four population controls, matched by age at type 1 diabetes diagnosis and residential community, who were alive at the time of diagnosis of the case [23].

The study was approved by the Regional Ethics Review Board at Umeå University and by the ethics committees at the National Board of Health and Statistics Sweden, respectively.

Data in the NDR and HDR are at the individual level, whereas the LMR contains data both at individual and household levels. The NDR is maintained by the National Board of Health and Welfare and contains, since 1 July 2005, individual data on pharmaceutical drugs dispensed through Swedish pharmacies prescribed by physicians, dentists and other licensed healthcare personnel. Each pharmaceutical product prescribed and dispensed for personal use is recorded with its name, the anatomical therapeutic chemical (ATC) code [24], date of prescription, date of collection by the patient, amount and price, together with the unique PIN for the individual for whom the drug was prescribed. The information is sent automatically from the local pharmacies to the NDR database. Missing or incomplete data are found in $<0.5 \%$ of cases [25].

The HDR, also maintained by the National Board of Health and Welfare, contains individual level data, using the unique PIN for the person being admitted to hospital, on date of admission for in-patient hospital care, date of discharge and main diagnosis at discharge.

The LMR is a database maintained by Statistics Sweden containing individual as well as household level data, again using the unique PIN of the person for whom information is collected. The database accumulates data on demographics, education, employment and income, including that from 
salaries and various benefits, e.g. sick leave compensation, unemployment benefits, pensions and social support. The information in the database is collected prospectively from several official sources and extensively matched to ensure validity [26]. Several of the socioeconomic markers used in the present analysis are based on multiple variables in the LMR database, e.g. one which states that a person has received unemployment benefits yes/no and a second one which states what amounts have been paid in unemployment benefits to that person. We cross-checked all such variables to ensure validity. The Swedish educational system has 9 years of compulsory schooling followed by 3 years of voluntary high school. After high school, graduates can proceed to college or university.

From the NDR, all individuals indexed in the SCDR as having type 1 diabetes, and control subjects who were alive and 18 years of age or older on 1 January 2006, were assessed as to whether they had been prescribed and collected ADs (ATC codes N06AA-N06AX) at any time during the period 1 January 2006 to 31 December 2007. From the LMR, data were collected on education (highest attained), income, family size (number of children), employment status (including receipt of unemployment benefits, social benefits or disability pension), and parental education, income, and their receipt of unemployment benefits, social benefits, and disability pension during 2005 (i.e. the year before AD prescription). From the HDR, any discharge from hospital during the period 1 January 2004 to 31 December 2005 was registered together with the main hospital diagnosis according to ICD-10 (www.who.int/classifications/icd/en/) [27]. Somatic diagnoses were defined as the main diagnosis made at discharge excluding psychiatric (ICD-10 codes F00-F99), obstetric (ICD-10 codes O00-O99) and perinatal (ICD-10 codes P00-P96) diagnoses. The somatic diagnoses include in-hospital care for type 1 diabetes. A diagnosis of depression at discharge included the ICD-10 codes F31-34, F38, F39 and F41.

Statistical analyses Descriptive data are presented as means and SDs or as frequencies. Logistic regression models were fitted with prescription of $\mathrm{AD}$ as the dependent variable in the type 1 diabetes and control cohorts separately, using PASW 18.0. Missing data were removed from the analysis. The level of missing data was low, for most variables $<2.5 \%$. However, the variables of paternal social welfare and disability pension had $12.2 \%$ missing values. Associations with covariates are measured with ORs and are presented with 95\% CIs. Covariates of known or suspected relation to the risk of being prescribed $\mathrm{AD}$ were first investigated univariately, and if significant they were entered step-wise into a multivariate logistic regression model. The models were subsequently stratified by sex. The final model is a joint model for both type 1 diabetes and control cohorts. Here, the presence of type 1 diabetes starting in childhood was explored as a risk factor for prescription of $\mathrm{AD}$, both in a univariate and a multivariate model.

\section{Results}

Basic characteristics In the type 1 diabetes cohort there were 7,411 and in the control cohort 30,043 individuals who were $\geq 18$ years of age and alive on 1 January 2006 (Table 1). There was a slight male predominance in both groups. Mean and maximum ages in the type 1 diabetes and control cohorts were similar, but the relative frequencies of several of the socioeconomic and health related factors differed between the type 1 diabetes and control groups. Fewer in the type 1 diabetes group had children or had education beyond high school. The proportion having been on sick leave or receiving disability pension and social support was higher in the type 1 diabetes cohort. Also, a higher proportion among the type 1 diabetes cohort had been discharged from hospital, either with a somatic or a depression diagnosis. Among the parental background characteristics, only parental age differed, where both paternal and maternal ages were significantly higher in the type 1 diabetes group.

Univariate risk factors for $A D$ prescription The distribution of risk factors associated with having been prescribed ADs during the 2 year study period was similar in the two cohorts (Table 2), with female sex, having been discharged with a diagnosis of depression from hospital, having received support socially or economically, and receiving disability pension showing the strongest association to $\mathrm{AD}$ prescription in terms of ORs. In both cohorts, the prescription of ADs was related to sex, with women being at least twice as likely to be prescribed ADs as men, and age, with increasing age being linked to a higher risk. Not having children was associated with a higher risk of AD prescription, but in the sex-stratified analysis in the control group, this risk was statistically significant in men only (OR 1.5, 95\% CI 1.29 , 1.75; women, OR 1.1, 95\% CI 0.99, 1.25).

Impaired socioeconomic status, as mirrored by unemployment or requirement for social support, was associated with higher AD prescription risk. Health related factors, such as any periods of sick leave in the year prior to being prescribed $\mathrm{AD}$, receiving disability pension or having been discharged from hospital with a somatic or depression diagnosis were all associated with increased risk of AD prescription. For both sick leave and receiving disability pension there was significant sex interaction, as male sex was associated with higher risk.

As expected, the number of hospitalisations was higher in the type 1 diabetes group than in the control group, but for 
Table 1 Socioeconomic, health related and parental characteristics of adults with childhood onset type 1diabetes mellitus and age- and communitymatched population controls

\begin{tabular}{|c|c|c|c|}
\hline Variable & $\mathrm{T} 1 \mathrm{DM}(n=7,411)$ & Controls $(n=30,043)$ & $p$ for difference between groups \\
\hline Prescription for $\mathrm{ADs}^{\mathrm{a}}, n(\%)^{\mathrm{b}}$ & $707(9.5)$ & $2,047(6.8)$ & $<0.001$ \\
\hline Female, $n(\%)$ & $3,522(47.5)$ & $14,787(49.2)$ & 0.009 \\
\hline Age, mean (SD; range) & $27.7(6.23 ; 18-43)$ & $27.8(6.26 ; 18-44)$ & 0.42 \\
\hline Having children, $n(\%)^{\mathrm{c}}$ & $3,578(50.7)$ & $15,904(52.9)$ & $<0.001$ \\
\hline No. of children, median (range) ${ }^{c}$ & $1(0-7)$ & $1(0-9)$ & $<0.001$ \\
\hline Education $>$ high school, $n(\%)^{\mathrm{c}}$ & $2,079(28.1)$ & $9,236(30.7)$ & $<0.001$ \\
\hline Any sick leave, $n(\%)^{\mathrm{c}}$ & $1,064(14.4)$ & $2,632(8.8)$ & $<0.001$ \\
\hline Any unemployment, $n(\%)^{\mathrm{c}}$ & $1,074(14.5)$ & 4,096 (13.6) & 0.13 \\
\hline Receiving disability pension, $n(\%)^{\mathrm{c}}$ & $435(5.9)$ & $787(2.7)$ & $<0.001$ \\
\hline Any social support, $n(\%)^{\mathrm{c}}$ & $505(6.8)$ & $1,624(5.4)$ & $<0.001$ \\
\hline \multicolumn{4}{|l|}{ Diagnosis at hospital discharge $(n)$} \\
\hline Somatic $d x^{d}$ & $1,580(21.3)$ & $1,976(6.6)$ & $<0.001$ \\
\hline Depression $\mathrm{dx}^{\mathrm{d}}$ & $41(0.6)$ & $94(0.3)$ & 0.002 \\
\hline Age at T1DM dx, mean (SD; range) & $9.7(3.62 ; 0-15)$ & NA & \\
\hline \multicolumn{4}{|l|}{ Parental details } \\
\hline Paternal age at birth of child, mean (SD) & $30.7(6.02)$ & $30.3(6.01)$ & 0.005 \\
\hline Maternal age at birth of child, mean (SD) & $27.8(5.23)$ & $27.3(5.20)$ & $<0.001$ \\
\hline Paternal education $>$ high school, $n(\%)^{\mathrm{c}}$ & $1,630(22.0)$ & $6,622(22.0)$ & 0.36 \\
\hline Maternal education $>$ high school, $n(\%)^{\mathrm{c}}$ & $2,031(27.4)$ & $8,174(27.2)$ & 0.49 \\
\hline Single mother as only caregiver, $n(\%)^{\mathrm{c}}$ & $690(9.3)$ & $2,807(9.3)$ & 0.65 \\
\hline Paternal sick leave, $n(\%)^{\mathrm{c}}$ & $718(9.7)$ & $2,949(9.8)$ & 0.46 \\
\hline Maternal sick leave, $n(\%)^{\mathrm{c}}$ & $1,298(17.5)$ & $5,062(16.8)$ & 0.53 \\
\hline Paternal disability pension, $n(\%)^{\mathrm{c}}$ & $758(10.2)$ & $3,017(10.0)$ & 0.98 \\
\hline Maternal disability pension, $n(\%)^{\mathrm{c}}$ & $1,330(17.9)$ & $5,100(17.0)$ & 0.22 \\
\hline Either parent receiving social support, $n(\%)^{\mathrm{c}}$ & $369(5.0)$ & $1,559(5.2)$ & 0.34 \\
\hline
\end{tabular}

$\mathrm{dx}$, diagnosis; T1DM, type 1 diabetes mellitus

${ }^{a}$ AD medication

${ }^{\mathrm{b}}$ From 1 January 2006 to 31 December 2007; ${ }^{\mathrm{c}}$ during 2005; ${ }^{\mathrm{d}}$ discharged from hospital from 1 January 2004 to 31 December 2005

both groups, hospitalisation for a somatic diagnosis was a risk factor for $\mathrm{AD}$. In addition, the number of hospitalisations for depression was higher in the type 1 diabetes group ( $0.6 \%$ vs $0.3 \%$, Fisher's exact test $p=0.002$, in the type 1 diabetes and control group, respectively). However, it was a significant risk factor for $\mathrm{AD}$ prescription in both groups. There was no significant interaction between sex and either hospitalisation for a somatic diagnosis or hospitalisation for depression. Neither age at diagnosis of type 1 diabetes nor duration of diabetes was associated with the risk of being prescribed ADs (data not shown).

In the control cohort, maternal education beyond 12 years of schooling was associated with a lower risk for AD prescription in the progeny (OR $0.8,95 \% \mathrm{CI} 0.76,0.94)$, with a similar, but non-significant tendency in the type 1 diabetes group (OR $0.8,95 \%$ CI $0.71,1.02$ ). Paternal education beyond 12 years of schooling was not associated with the risk of $\mathrm{AD}$ prescription (data not shown). Parental factors lowering the socioeconomic status and associated with parental poor health were significantly associated with higher risk, among the children, of being prescribed ADs in both the type 1 diabetes and control groups (Table 2). Parental age was not associated with risk for AD prescription (data not shown).

Multivariate, within group analyses The multivariate models for the type 1 diabetes and control groups respectively (Table 3) show similar patterns of risk factors for AD prescription, with hospitalisation for depression and being on disability pension or on sick leave having the highest ORs. In both groups, having an education beyond high school and the mother being on sick leave become non-significant in the multivariate model.

Secondary, pooled multivariate analysis In a secondary analysis of our case-control design, we pooled type 1 
Table 2 Univariate and sex-stratified logistic regressions for prescription of AD medication (dependent variable) for adults with childhood onset type 1 diabetes mellitus and age- and community-matched population controls

\begin{tabular}{|c|c|c|c|c|c|c|}
\hline \multirow[t]{2}{*}{ Variable } & \multicolumn{3}{|l|}{ T1DM } & \multicolumn{3}{|l|}{ Controls } \\
\hline & Male $(n=3,889)$ & $\begin{array}{l}\text { Female } \\
(n=3,522)\end{array}$ & $\begin{array}{l}\text { Sexes combined } \\
(n=7,411)\end{array}$ & $\begin{array}{l}\text { Male } \\
(n=15,256)\end{array}$ & $\begin{array}{l}\text { Female } \\
(n=14,787)\end{array}$ & $\begin{array}{l}\text { Sexes combined } \\
(n=30,043)\end{array}$ \\
\hline Female sex & NA & NA & $2.5(2.11,2.94)$ & NA & NA & $2.1(1.90,2.30)$ \\
\hline Age & $1.04(1.02,1.06)$ & $1.02(1.01,1.04)$ & $1.03(1.02,1.04)$ & $1.03(1.02,1.04)$ & $1.02(1.00,1.03)$ & $1.02(1.01,1.03)$ \\
\hline Not having children ${ }^{\mathrm{a}}$ & $1.5(1.13,1.95)$ & $1.3(1.06,1.57)$ & $1.3(1.11,1.52)$ & $1.5(1.29,1.75)$ & $1.1(0.99,1.25)$ & $1.2(1.09,1.30)$ \\
\hline Education $>$ high school $^{\text {a }}$ & $0.7(0.52,1.03)$ & $0.6(0.46,0.72)$ & $0.7(0.57,0.83)$ & $0.8(0.69,0.99)$ & $0.7(0.63,0.80)$ & $0.8(0.73,0.90)$ \\
\hline Any sick leave $\mathrm{e}^{\mathrm{a}}$ & $5.1(3.73,6.87)$ & $2.6(2.10,3.19)$ & $3.7(3.08,4.34)$ & $4.5(3.68,5.61)$ & $2.8(2.45,3.19)$ & $3.6(3.25,4.05)$ \\
\hline Any unemployment ${ }^{\mathrm{a}}$ & $1.7(1.19,2.37)$ & $1.2(0.96,1.57)$ & $1.5(1.19,1.77)$ & $1.2(0.93,1.44)$ & $1.3(1.12,1.49)$ & $1.3(1.16,1.48)$ \\
\hline Disability pension $^{\mathrm{a}}$ & $5.5(3.77,8.10)$ & $3.6(2.77,4.81)$ & $4.5(3.62,5.66)$ & $7.0(5.38,9.00)$ & $4.5(3.62,5.56)$ & $5.4(4.58,6.36)$ \\
\hline Social support ${ }^{\mathrm{a}}$ & $2.0(1.32,3.00)$ & $3.4(2.56,4.60)$ & $2.7(2.14,3.40)$ & $2.9(2.29,3.60)$ & $2.6(2.16,3.15)$ & $2.6(2.27,3.02)$ \\
\hline $\begin{array}{l}\text { Somatic dx at } \\
\text { discharge }\end{array}$ & $2.1(1.57,2.80)$ & $2.5(2.07,3.10)$ & $2.5(2.12,2.93)$ & $1.9(1.44,2.38)$ & $2.4(2.01,2.82)$ & $2.2(1.94,2.56)$ \\
\hline $\begin{array}{l}\text { Depression } \mathrm{dx} \\
\text { at discharge }\end{array}$ & $32.6(8.11,131.4)$ & $9.7(4.75,19.7)$ & $15.3(8.14,28.84)$ & $22.5(12.49,40.6)$ & $12.5(7.07,21.9)$ & $15.9(10.58,23.91$ \\
\hline Age at diabetes $d x$ & $1.0(0.98,1.06)$ & $1.0(0.98,1.03)$ & $1.0(0.98,1.03)$ & NA & NA & NA \\
\hline $\begin{array}{l}\text { Single mother as } \\
\text { only caregiver }^{\mathrm{a}}\end{array}$ & $1.6(1.10,2.44)$ & $1.6(1.18,2.12)$ & $1.6(1.26,2.02)$ & $1.4(1.08,1.74)$ & $1.3(1.11,1.58)$ & $1.3(1.17,1.55)$ \\
\hline Paternal sick leave $^{\mathrm{a}}$ & $1.6(1.08,2.41)$ & $1.2(0.88,1.68)$ & $1.3(1.04,1.71)$ & $1.2(0.94,1.54)$ & $1.3(1.13,1.60)$ & $1.3(1.12,1.48)$ \\
\hline Maternal sick leave ${ }^{\mathrm{a}}$ & $1.4(0.98,1.90)$ & $1.2(0.97,1.58)$ & $1.3(1.06,1.56)$ & $1.1(0.89,1.33)$ & $1.2(1.06,1.41)$ & $1.2(1.04,1.32)$ \\
\hline $\begin{array}{l}\text { Paternal disability } \\
\text { pension }^{\mathrm{a}}\end{array}$ & $2.2(1.56,3.20)$ & $1.9(1.40,2.47)$ & $1.9(1.55,2.41)$ & $1.5(1.18,1.86)$ & $1.6(1.36,1.89)$ & $1.6(1.36,1.77)$ \\
\hline $\begin{array}{l}\text { Maternal disability } \\
\text { pension }^{\mathrm{a}}\end{array}$ & $2.0(1.50,2.76)$ & $1.6(1.28,2.03)$ & $1.8(1.46,2.10)$ & $1.6(1.35,1.94)$ & $1.6(1.36,1.78)$ & $1.6(1.41,1.75)$ \\
\hline $\begin{array}{l}\text { Either parent receiving } \\
\text { social support }\end{array}$ & $1.5(0.90,2.60)$ & $1.6(1.10,2.38)$ & $1.6(1.17,2.15)$ & $1.7(1.26,2.19)$ & $1.7(1.36,2.10)$ & $1.6(1.38,1.93)$ \\
\hline
\end{tabular}

Data are OR $(95 \% \mathrm{CI})$

$\mathrm{dx}$, diagnosis; NA, not applicable; T1DM, type 1 diabetes mellitus

${ }^{\mathrm{a}}$ During 2005; ${ }^{\mathrm{b}}$ diagnosis at discharge from hospital from 1 January 2004 to 31 December 2005

diabetes cases and controls to further analyse whether type 1 diabetes is an independent risk factor for $\mathrm{AD}$ prescription (Table 4). In univariate analysis, type 1 diabetes was associated with a 44\% higher risk (OR 1.44, 95\% CI 1.32, 1.58). When adjusting for the potential confounders, including sex, age and various socioeconomic risk factors, this risk increase was no longer statistically significant (OR 1.11, 95\% CI 0.99 , 1.24). Hospitalisation for depression, receiving disability pension, having been on sick leave, and receiving social support remained factors with the strongest association with being prescribed AD. Interaction terms for diabetes and the socioeconomic variables were investigated and found to be not significant (data not shown).

\section{Discussion}

In the present large sample of young adults, the presence of childhood onset type 1 diabetes was associated with a $44 \%$ increased risk of receiving $\mathrm{AD}$ compared with matched non- diabetic individuals. This estimate of increased risk is in agreement with, or slightly lower than, other reports indicating that diabetes is a risk factor for depression [3-5]. The higher prevalence reported in some reports is probably due to differences in age range, as the present study included a younger age group. In separate analyses, the patterns of risk factors associated with prescription of $\mathrm{AD}$ were similar in the type 1 diabetes and control cohorts. In a secondary analysis, combining the two cohorts and adjusting for well-known, mainly socioeconomic and general health related, risk factors for depression such as hospitalisations, sick leave and receiving disability pension, having type 1 diabetes was only associated with a small increase in risk that did not reach statistical significance. There was no statistically significant interaction between type 1 diabetes and the socioeconomic variables, indicating that the impact of socioeconomic status on $\mathrm{AD}$ usage was not dependent on the presence of diabetes (i.e. there was no effect modification). Psychiatric illnesses (ICD-10 codes F00-F99) were the most common reasons for both sick leave and disability pension in 
Table 3 Multivariate logistic regression for prescription of AD medication (dependent variable) for adults with childhood onset type 1 diabetes mellitus and age- and community-matched population controls, respectively

\begin{tabular}{|c|c|c|}
\hline Variable & $\mathrm{T} 1 \mathrm{DM}(n=7,411)$ & Controls $(n=30,043)$ \\
\hline Female sex & $2.3(1.87,2.77)$ & $2.0(1.77,2.20)$ \\
\hline Age (years) & $1.0(0.99,1.02)$ & $1.0(1.00,1.02)$ \\
\hline Not having children ${ }^{\mathrm{a}}$ & $1.3(1.07,1.55)$ & $1.2(1.09,1.35)$ \\
\hline Education $>$ high school $^{\mathrm{a}}$ & $0.8(0.66,1.03)$ & $0.9(0.80,1.02)$ \\
\hline Any sick leave ${ }^{a}$ & $2.7(2.20,3.41)$ & $2.6(2.30,3.02)$ \\
\hline Any unemployment ${ }^{\mathrm{a}}$ & $1.4(1.07,1.72)$ & $1.3(1.09,1.44)$ \\
\hline Disability pension $^{\mathrm{a}}$ & $3.4(2.50,4.69)$ & $5.2(4.16,6.47)$ \\
\hline Social support ${ }^{\mathrm{a}}$ & $2.4(1.77,3.15)$ & $2.4(1.98,2.82)$ \\
\hline $\begin{array}{l}\text { Somatic dx at } \\
\text { discharge }^{\mathrm{b}}\end{array}$ & $1.6(1.29,1.94)$ & $1.3(1.12,1.59)$ \\
\hline $\begin{array}{l}\text { Depression dx } \\
\text { at discharge }\end{array}$ & $6.6(3.05,14.29)$ & $5.7(3.37,9.61)$ \\
\hline \multicolumn{3}{|l|}{ Parental details } \\
\hline Paternal sick leave $^{a}$ & $1.2(0.89,1.53)$ & $1.2(1.02,1.39)$ \\
\hline Maternal sick leave $^{a}$ & $1.2(0.92,1.44)$ & $1.1(0.99,1.28)$ \\
\hline $\begin{array}{l}\text { Paternal disability } \\
\text { pension }^{\mathrm{a}}\end{array}$ & $1.6(1.25,2.06)$ & $1.2(1.07,1.44)$ \\
\hline $\begin{array}{l}\text { Maternal disability } \\
\text { pension }^{\mathrm{a}}\end{array}$ & $1.3(1.08,1.67)$ & $1.2(1.10,1.41)$ \\
\hline
\end{tabular}

Data are OR $(95 \% \mathrm{CI})$

$\mathrm{dx}$, diagnosis; T1DM, type 1 diabetes mellitus

${ }^{a}$ During 2005; ${ }^{b}$ diagnosis at discharge from hospital from 1 January 2004 to 31 December 2005

Table 4 Multivariate logistic regression for prescription of AD medication (dependent variable) for adults with childhood onset type 1 diabetes mellitus and age- and community-matched population controls combined

\begin{tabular}{ll}
\hline Variable & OR $(95 \% \mathrm{CI})$ \\
\hline Diabetes mellitus & $1.1(0.99,1.24)$ \\
Female sex & $2.0(1.81,2.19)$ \\
Not having children $^{\mathrm{a}}$ & $1.2(1.12,1.35)$ \\
Any unemployment $^{\mathrm{a}}$ & $1.3(1.15,1.45)$ \\
Social support $^{\mathrm{a}}$ & $2.4(2.04,2.73)$ \\
Any sick leave $^{\mathrm{a}}$ & $2.8(2.48,3.11)$ \\
Disability pension $^{\mathrm{a}}$ & $4.1(3.51,4.89)$ \\
Somatic dx at discharge $^{\mathrm{b}}$ & $1.4(1.26,1.63)$ \\
Depression dx at discharge $^{\mathrm{b}}$ & $6.2(4.01,9.46)$ \\
Paternal sick leave $^{\mathrm{a}}$ & $1.2(1.05,1.36)$ \\
Maternal sick leave $^{\mathrm{a}}$ & $1.1(1.01,1.26)$ \\
Paternal disability pension $^{\mathrm{a}}$ & $1.3(1.16,1.49)$ \\
Maternal disability pension $^{\mathrm{a}}$ & $1.3(1.18,1.46)$
\end{tabular}

$\mathrm{dx}$, diagnosis

${ }^{a}$ During 2005; ${ }^{b}$ diagnosis at discharge from hospital from 1 January 2004 to 31 December 2005 young adults as well as in the older age groups (i.e. the parents) and explain in total some $25 \%$ of disability pensions (personal communication, A. Kolk, National Social Insurance system, Unit for Statistical Analysis). Among young adults, mood disorders including depression contribute to $16 \%$ of disability pensions [28]. We do not have information on somatic or psychiatric illness in the parents, which we believe would have contributed significantly to the model, further decreasing the effect of diabetes [29]. However, we did include indicators of parental socioeconomic status, including parental sick leave and disability pension, which were found to be significantly associated with $\mathrm{AD}$ prescription in their children. Low socioeconomic status in parents is a wellknown risk factor for poor health, including depression, in the offspring $[30,31]$. Although the present study cannot clearly answer the question of whether low socioeconomic status in the present setting leads to depression or vice versa, prospective studies indicate that lower socioeconomic status increases the risk of subsequent depression [32].

These results indicate that diabetes per se (i.e. aberrations in glucose metabolism) is not clearly associated with an increased risk of depression, as previously suggested [1]. The increase in risk in young people with diabetes compared with age-matched controls would thus mainly depend on their higher prevalence of socioeconomic risk factors, which is in contrast to previous studies. The exact mechanism through which type 1 diabetes contributes to this higher prevalence of socioeconomic risk factors still remains to be elucidated, although two reviews point towards the negative effect of type 1 diabetes in educational achievements and adult employment [33, 34]. Chronic poor health in childhood may, per se, be a factor in academic underachievement and difficulties in becoming established on the labour market [31]. We have previously shown, in data from the SCDR, that children with type 1 diabetes have lower school marks than reference children [35], but also that children of mothers who had childhood onset type 1 diabetes have lower school marks [36].

The present register study used prescribed and dispatched AD medicine as a proxy for depression and clearly the individual cause for being prescribed such medicine may vary, although depression is the most common indication for $\mathrm{AD}$ use [37]. In diabetes, as well as in other chronic medical conditions, psychiatric co-morbidity, such as clinical depression, may be under-diagnosed as well as under-treated, despite the fact that both depressive symptoms and glycaemic control respond well to both pharmacological and psychotherapeutic treatment [38]. In a recent population-based study from Finland [39] AD prescription was studied over a 10 year period (1997-2007) in diabetes cases, including all types and age groups, using a nationwide prescription register similar to the Swedish one. That study found that $\mathrm{AD}$ use was more common among diabetic compared with non- 
diabetic individuals, and the risk increases were similar to those in our study (RR 1.5-1.6 in both men and women, 1544 years of age). Importantly, there was a rapid prevalence increase among the youngest age groups. Our prevalence data on $\mathrm{AD}$ prescription in the control group are similar to those recently published on AD use among Swedish 2034 year olds [40] and our findings that a hospital diagnosis of depression was strongly associated with $\mathrm{AD}$ prescription supports the use of AD as a proxy for depression. Gendelman and co-workers [41] reported that $14.5 \%$ of type 1 diabetic men and $20.1 \%$ of type 1 diabetic women scored high enough on the Beck Depression Inventory (BDI) II to be classified as being at least mildly depressed, without being under treatment, compared with $3.6 \%$ of nondiabetic men and $7.8 \%$ of non-diabetic women. This may indicate that our study only captured the more severe cases.

The strength of our study is that it is exceptionally large and population based and that it was possible to link data from official administrative registers measuring socioeconomic factors at an individual level. In addition, the data on AD use have high validity, coming from automatic, individual level, actual prescription and collection records gathered from nationwide surveillance at local pharmacies, reducing recall bias and the missing information that comes from a reluctance to surrender sensitive facts in questionnaires and interviews. However, we cannot oversee the possibility that there are random validity problems when using official register data. Thus, we interpret the findings in the present study as showing that it is the sum of the socioeconomic variables that affect $\mathrm{AD}$ prescription, not putting emphasis on any specific variable. Furthermore, depression of such magnitude that it requires $\mathrm{AD}$ medication indicates more severe cases, and the associations between ADs and socioeconomic factors found in the present study may not be relevant in milder forms of depression. Still, the results give firm information on the socioeconomic risk factors for $\mathrm{AD}$ and clearly, already at very young age, such risk factors are more prevalent among type 1 diabetic patients.

In conclusion, the present study does not support the theory that childhood onset type 1 diabetes per se is a risk factor for mood disorders that lead to increased use of ADs, but that socioeconomic risk factors for such use are more prevalent in young people with diabetes than in controls. The message is then that diabetes clinics must be aware of this, and try to prevent long term sick leave and disability pension and, from an early age, work closely with social services, since social deprivation in diabetes may lead to co-morbidity such as depression, possibly instigating the vicious circle of depressed mood, poor metabolic control and diabetes-related complications.

Acknowledgements This study was supported by the Swedish Research Council (project no. 07531 DG)
Contribution statement TL was the main author of the paper and contributed to the design of the study, the analyses and interpretation of the data, and drafting and revising the paper. IW contributed in the conception and design of the study, the analyses and interpretation of the data, and in the writing of the manuscript. YB contributed in the analysis of the data and in the writing of the manuscript. GD is the principal investigator in SCDR. GD contributed in the conception and design of the study, the interpretation of data, and the writing of the manuscript. All authors gave final approval to the published version of this paper.

Duality of interest All authors declare that there is no duality of interest associated with this manuscript.

\section{References}

1. Lustman PJ, Clouse RE (2005) Depression in diabetic patients: the relationship between mood and glycemic control. J Diabetes Complications 19:113-122

2. van Tilburg MA, McCaskill CC, Lane JD et al (2001) Depressed mood is a factor in glycemic control in type 1 diabetes. Psychosom Med 63:551-555

3. Anderson RJ, Freedland KE, Clouse RE, Lustman PJ (2001) The prevalence of comorbid depression in adults with diabetes: a meta-analysis. Diabetes Care 24:1069-1078

4. Barnard KD, Skinner TC, Peveler R (2006) The prevalence of comorbid depression in adults with type 1 diabetes: systematic literature review. Diabet Med 23:445-448

5. Lawrence JM, Standiford DA, Loots B et al (2006) Prevalence and correlates of depressed mood among youth with diabetes: the SEARCH for Diabetes in Youth Study. Pediatrics 117:1348-1358

6. Kovacs M, Goldston D, Obrosky DS, Bonar LK (1997) Psychiatric disorders in youths with IDDM: rates and risk factors. Diabetes Care 20:36-44

7. Popkin MK, Callies AL, Lentz RD, Colon EA, Sutherland de (1988) Prevalence of major depression, simple phobia, and other psychiatric disorders in patients with long-standing type I diabetes mellitus. Arch Gen Psychiatry 45:64-68

8. Petrak F, Hardt J, Wittchen HU et al (2003) Prevalence of psychiatric disorders in an onset cohort of adults with type 1 diabetes. Diabetes Metab Res Rev 19:216-222

9. Kokkonen E-R (1995) Mental health and social adaptation in young adults with juvenile-onset diabetes. Nordic J Psychiatr 49:175-181

10. Lustman PJ, Griffith LS, Clouse RE et al (1995) Effects of alprazolam on glucose regulation in diabetes. Results of double-blind, placebo-controlled trial. Diabetes Care 18:1133-1139

11. Lustman PJ, Griffith LS, Clouse RE et al (1997) Effects of nortriptyline on depression and glycemic control in diabetes: results of a double-blind, placebo-controlled trial. Psychosom Med 59:241-250

12. Lustman PJ, Clouse RE, Griffith LS, Carney RM, Freedland KE (1997) Screening for depression in diabetes using the Beck Depression Inventory. Psychosom Med 59:24-31

13. Garrison CZ, Addy CL, Jackson KL, McKeown RE, Waller JL (1992) Major depressive disorder and dysthymia in young adolescents. Am J Epidemiol 135:792-802

14. Goodman E (1999) The role of socioeconomic status gradients in explaining differences in US adolescents' health. Am J Public Health 89:1522-1528

15. Roberts RE, Roberts CR, Chen YR (1997) Ethnocultural differences in prevalence of adolescent depression. Am J Community Psychol 25:95-110 
16. Hansen DG, Sondergaard J, Vach W et al (2004) Socio-economic inequalities in first-time use of antidepressants: a population-based study. Eur J Clin Pharmacol 60:51-55

17. Berhan Y, Waernbaum I, Lind T, Möllsten A, Dahlquist G (2011) Thirty years of prospective nationwide incidence of childhood type 1 diabetes: the accelerating increase by time tends to level off in Sweden. Diabetes 60:577-581

18. Dahlquist G, Mustonen L (2000) Analysis of 20 years of prospective registration of childhood onset diabetes time trends and birth cohort effects. Swedish Childhood Diabetes Study Group. Acta Paediatr 89:1231-1237

19. Wallgren A, Wallgren B (2007) Register-based statistics: administrative data for statistical purposes. Wiley, Chichester

20. The National Board of Health and Welfare (2011). www.socialstyrelsen. se/english. Accessed 9 September 2011

21. Statistics Sweden (2011). www.scb.se/default_2154.aspx. Accessed 9 September 2011

22. The National Board of Health and Welfare (2003) A finger on the pulse. Monitoring public health and social conditions in Sweden 1992-2002. In: Rosén M (ed). The National Board of Health and Welfare, Stockholm

23. Ury HK (1975) Efficiency of case-control studies with multiple controls per case: continuous or dichotomous data. Biometrics 31:643-649

24. World Health Organization Collaborating Centre for Drug Statistics Methodology (2011) ATC/DDD Index 2011. www.whocc.no/. Accessed 9 September 2011

25. The National Board of Health and Welfare (2007) Pharmaceuticals — statistics for 2006. In: Eriksson Ö (ed). The National Board of Health and Welfare, Stockholm

26. Statistics Sweden (2011) Background facts, labour and education statistics 2011:4. In: Integrated database for labour market research. SCB, Stockholm

27. World Health Organization (2007) International statistical classification of diseases and related health problems, 10th revision. http://apps.who.int/classifications/apps/icd/icd10online/. Accessed 9 September 2011

28. Inspektionen för socialförsäkringen (2011) Unga med aktivitetsersättning. In: Inspektionen för socialförsäkringen, Stockholm (in Swedish)

29. Li X, Sundquist J, Sundquist K (2008) Age-specific familial risks of depression: a nation-wide epidemiological study from Sweden. J Psychiatr Res 42:808-814
30. Barrera MJ, Prelow HM, Dumka LE et al (2002) Pathways from family economic conditions to adolescents' distress: supportive parenting, stressors outside the family, and deviant peers. J Community Psychol 30:135-152

31. Currie J (2009) Healthy, wealthy, and wise: socioeconomic status, poor health in childhood, and human capital development. J Econ Lit 47:87-122

32. Sundquist K, Johansson LM, Johansson SE, Sundquist J (2004) Social environment and psychiatric illness. A follow-up study of 9,170 women and men in Sweden. Soc Psychiatr Psychiatr Epidemiol 39:39-44

33. Milton B, Holland P, Whitehead M (2006) The social and economic consequences of childhood-onset type 1 diabetes mellitus across the lifecourse: a systematic review. Diabet Med 23:821829

34. Kakleas K, Kandyla B, Karayianni C, Karavanaki K (2009) Psychosocial problems in adolescents with type 1 diabetes mellitus. Diabetes Metab 35:339-350

35. Dahlquist G, Kallen B (2007) School performance in children with type 1 diabetes - a population-based register study. Diabetologia 50:957-964

36. Dahlquist G, Kallen B (2007) School marks for Swedish children whose mothers had diabetes during pregnancy: a population-based study. Diabetologia 50:1826-1831

37. Henriksson S, Boethius G, Hakansson J, Isacsson G (2003) Indications for and outcome of antidepressant medication in a general population: a prescription database and medical record study, in Jamtland county, Sweden, 1995. Acta Psychiatr Scand 108:427431

38. van der Feltz-Cornelis CM, Nuyen J, Stoop C et al (2010) Effect of interventions for major depressive disorder and significant depressive symptoms in patients with diabetes mellitus: a systematic review and meta-analysis. Gen Hosp Psychiatry 32:380-395

39. Manderbacka K, Sund R, Koski S, Keskimaki I, Elovainio M (2011) Diabetes and depression? Secular trends in the use of antidepressants among persons with diabetes in Finland in 19972007. Pharmacoepidemiol Drug Saf 20:338-343

40. Sundell KA, Gissler M, Petzold M, Waern M (2011) Antidepressant utilization patterns and mortality in Swedish men and women aged 20-34 years. Eur J Clin Pharmacol 67:169-178

41. Gendelman N, Snell-Bergeon JK, McFann K et al (2009) Prevalence and correlates of depression in individuals with and without type 1 diabetes. Diabetes Care 32:575-579 